\title{
Handgrip strength, quadriceps muscle power, and optimal shortening velocity roles in maintaining functional abilities in older adults living in a long- term care home: a I-year follow-up study
}

\author{
This article was published in the following Dove Press journal: \\ Clinical Interventions in Aging \\ 26 May 2016 \\ Number of times this article has been viewed
}

\section{Izabela Kozicka \\ Tomasz Kostka}

Department of Geriatrics, Medical University of Lodz, Lodz, Poland
Correspondence: Izabela Kozicka Department of Geriatrics, Medical University of Lodz, Żeromskiego Street I I3, 90-549 Lodz, Poland

Tel +48505 I5। 062

Email isabel.kozicka@gmail.com
Purpose: To assess the relative role of handgrip strength (HGS), quadriceps muscle power $\left(\mathrm{P}_{\max }\right)$, and optimal shortening velocity $\left(\mathrm{v}_{\mathrm{opt}}\right)$ in maintaining functional abilities (FAs) in older adults living in a long-term care home over a 1-year follow-up.

Subjects and methods: Forty-one inactive older institutionalized adults aged $69.8 \pm 9.0$ years participated in this study. HGS, $\mathrm{P}_{\max }, v_{\text {opt }}$, cognitive function using the Mini-Mental State Examination, depressive symptoms using the Geriatric Depression Scale, nutritional status using the Mini Nutritional Assessment (MNA), and physical activity (PA) using the Seven-Day Physical Activity Recall Questionnaire were assessed at baseline and at 1-year follow-up. FAs were assessed with activities of daily living (ADL), instrumental ADL, and Timed Up \& Go test.

Results: Both at baseline and at follow-up, FAs were related to age, HGS, $\mathrm{P}_{\max } / \mathrm{kg}, v_{\text {opt }}$, MNA, and PA. These associations were generally similar in both sexes. As revealed in multiple regression analysis, $v_{\text {opt }}$ was the strongest predictor of FA, followed by $\mathrm{P}_{\max } / \mathrm{kg}, \mathrm{PA}$, and MNA. FA deteriorated after 1 year as measured by ADL and Timed Up \& Go test. $P_{\max }$ and $v_{\text {opt }}$, but not HGS, also decreased significantly after 1 year. Nevertheless, 1-year changes in FAs were not related to changes in HGS, $\mathrm{P}_{\max }, v_{\text {opt }}$, or PA.

Conclusion: The 1-year period of physical inactivity among older institutionalized adults was found to have a negative effect on their FAs, $\mathrm{P}_{\max }$, and $v_{\text {opt }}$. The present study demonstrates that $\mathrm{P}_{\max }$ and, especially, $v_{\text {opt }}$ correlated with FAs of older adults more than HGS, both at baseline and at follow-up. Despite this, 1-year natural fluctuations of PA, $\mathrm{P}_{\max }$, and $v_{\text {opt }}$ are not significant enough to influence FAs in inactive institutionalized older adults.

Keywords: aging, handgrip strength, institutionalization, functional status, physical activity

\section{Introduction}

In recent years, great attention has been paid to functional ability (FA) in scientific publications. The majority of these studies are dedicated to people of old age, which is generally associated with a progressive drop in physical and psychological health, increased risk of disability and dependency, and an increase in the number of morbidities. ${ }^{1-6}$ Functional disability is a predictor of institutionalization, ${ }^{7,8}$ worse quality of life, and increased mortality. 5,9

The role of muscle strength in maintaining independence has been confirmed by many studies, mainly in older adults. ${ }^{10}$ According to Reid et al, ${ }^{11}$ a loss of muscle strength with age is closely associated with decreasing FA. A certain amount of force is necessary to perform daily tasks such as walking, carrying shopping, unscrewing 
jars, using tools, or holding, for example, the handrail of entry stairs. ${ }^{12}$ Handgrip strength (HGS), a simple and reliable technique, has been commonly used as a measure of muscle functioning in the geriatric literature. ${ }^{13}$ However, the most important muscles that are necessary to maintain independence in activities of daily living (ADL) are the muscles of the lower limbs. ${ }^{14}$ In particular, the quadriceps muscles are responsible for performing basic tasks such as maintaining an upright position; walking, ascending, and descending stairs; and sitting down and getting up from a sitting position. ${ }^{15}$ Furthermore, in studies comparing the relationships between muscle strength and muscle power with FA, muscle power, which is the product of force and muscle shortening velocity, almost always seems to be a stronger determinant. ${ }^{10}$ Consequently, growing interest in the subject of muscle power $\left(\mathrm{P}_{\max }\right)$ and optimal shortening velocity $\left(v_{\text {opt }}\right)$ as measures of muscle functioning has been observed in recent years. ${ }^{4}$ The optimal shortening velocity has been found to be even a stronger predictor of FA than strength in one study. ${ }^{16}$ Physiologically, the decreasing quantity and quality of fast-twitch muscle fibers are mainly responsible for restricting FA in older people due to lower $v_{\text {opt }}$ and power. ${ }^{16-18}$

The available literature does not include studies that assessed HGS, $\mathrm{P}_{\text {max }}$, and $v_{\text {opt }}$ together in older adults residing in long-term care homes. Therefore, the objective of this study was to examine prospectively the impact of $\mathrm{P}_{\max }, v_{\text {opt }}$, HGS, and physical activity (PA) on the FA of older institutionalized adults. The following hypotheses were provided: 1) $P_{\max }$ and $v_{\text {opt }}$ are more important correlates of FA of older adults than HGS; 2) the higher PA level is associated with better $\mathrm{P}_{\max }, v_{\text {opt }}$, and FA; 3 ) changes in HGS, $\mathrm{P}_{\text {max }}, v_{\text {opt }}$, and PA over a 1-year period are related to FA of older institutionalized adults.

\section{Subjects and methods Participants}

The study group was selected from residents of a public nursing home in the city of Lodz, Poland. The study was conducted in two stages. The inclusion criteria of the study were as follows: 1) aged over 55 years; 2) logical and verbal contact; 3) no considerable hearing disorders significantly hampering understanding of questions at the time of the study; and 4) ability to perform exercise tests. Patients with cardiologic contraindications for exercise tests, motor system dysfunction (eg, limited range of motion, severe spasticity, and pain) and patients who did not give their informed consent to participate in the study were excluded. Consequently, among 595 residents of the nursing home, 371 aged 55 years and older were initially screened and recommended for participation in the study. Ultimately, the initial 371 subjects were reduced to 49 participants, because 205 were of limited verbal contact, 67 were not able to perform exercise tests, and 50 did not give consent to participate in the study. Therefore, 49 older subjects ( 19 women and 30 men) aged 55 years and older were selected for the first phase of the study.

Each subject underwent a multidimensional assessment, which included demographic and social parameters, health conditions, and physical and cognitive function. The following set of instruments commonly used for health assessments of older populations was utilized: 1) HGS, $\mathrm{P}_{\text {max }}$, and $v_{\text {opt }}$ as independent muscle function variables; 2) FAs as dependent variables; 3) cognitive function (Mini-Mental State Examination [MMSE]), depressive symptoms (15-item Geriatric Depression Scale [GDS]), nutritional status (Mini Nutritional Assessment [MNA]), and PA as supplementary variables potentially modifying the relationship between independent and dependent variables. All these questionnaires and tests were completed by researchers during a personal interview of $\sim 2.5$ hours, both at baseline and at follow-up. Furthermore, ADL and instrumental activities of daily living (IADL) questionnaires were verified with the medical staff.

Forty-one patients (17 women and 24 men) underwent two assessments, one at baseline and another at 1-year follow-up. Due to health status deterioration $(n=4)$, change in residence $(n=1)$, cancellation of consent to participate in the study $(n=1)$, and death $(n=2)$, eight of their original study group were only involved in the first examination. These patients were not included in a prospective analysis. All the participants led sedentary lifestyles, and none of them practiced regular PA during the 1-year follow-up.

\section{HGS measurements}

HGS was tested using a hydraulic hand dynamometer by Jamar $^{\circledR}$ (Sammons Preston Rolyan, Bolingbrook, Canada). The dynamometer facilitates measurements of isometric force to $90 \mathrm{~kg}$. According to the literature, the measurements are influenced by subject position when carrying out the test (lying, sitting, or standing). Previous studies have shown better results with a standing position. Therefore, all subjects carried out the HGS test in the standing position with shoulder adducted and neutrally rotated and elbow in $90^{\circ}$ flexion with no radioulnar deviation. The participants were required to squeeze the handle maximally and to sustain this for 1-2 seconds. All measurements were performed for 
both hands. Subjects performed three maximum attempts for each grip strength measurement, and the mean value of these trials was recorded. One-minute rests were given between each attempt, and hands were alternated to minimize fatigue effects. Results were recorded in kilogram force (kgf). ${ }^{13,19}$

\section{Power testing}

Mechanical measurements were carried out on a frictionloaded cycle ergometer (Ergomedic type 828E, Monark, Stockholm, Sweden). Measurements of $\mathrm{P}_{\max }$ and $v_{\text {opt }}$ using the ergometer have previously been described and validated in a population of older adults. ${ }^{18,20}$ The ergometer was instrumented with a strain gauge (FN3030 type, $20 \mathrm{daN}$; FGP Instrumentation, Les Clayes sous Bois, France) and with an incremental encoder (Hengstler type RIS IP50, 100 pts/turn; Aldingen, Germany) for measurement of the friction force applied by the tension of the belt that surrounds the flywheel. The strain gauge was calibrated with a known mass $(2.553 \mathrm{~kg})$. Flywheel inertia was calculated by the method suggested by Lakomy. ${ }^{21}$ For all experiments, the saddle height was adjusted to give optimal comfort for each subject and toe clips were removed to prevent any pulling action of the contralateral leg. After a 5-minute warm-up on the cycle ergometer, the subjects were asked to perform two 8-second sprints from a starting position, each separated by at least 5 minutes of rest. Friction loads were $0.25 \mathrm{~N} / \mathrm{kg}$ and $0.35 \mathrm{~N} / \mathrm{kg}$ of body mass, except in the case of the most disabled subjects, in whom friction loads of $0.15 \mathrm{~N} / \mathrm{kg}$ and $0.25 \mathrm{~N} / \mathrm{kg}$ of body mass were used. ${ }^{4,22}$ At the signal given by the investigator, the subjects were asked to pedal as fast as possible until told to stop (after 8 seconds). During the effort, each subject was vigorously encouraged. ${ }^{22}$ The highest value of $\mathrm{P}$ (maximum short-term power, $\mathrm{P}_{\max }$ ) and velocity at maximum power (optimal velocity, $v_{\text {opt }}$ ) were calculated from a third-order polynomial function. Maximum power is expressed as relative to body mass, $\mathrm{P}_{\text {max }} / \mathrm{kg}(\mathrm{W} / \mathrm{kg}) . v_{\text {opt }}$ is expressed as revolutions per minute (rpm).

\section{FA tests}

Using the ADL scale, ${ }^{23}$ the ability to perform the basic ADL (bathing, dressing, toilet, sphincter control, eating, and moving around) was evaluated. The number of points scored by the patient indicated full function (5-6 points), moderate impairment (3-4 points), and severe functional impairment ( $\leq 2$ points).

Using the IADL scale, ${ }^{24}$ the ability to perform complex ADL, such as using the phone, shopping, preparing meals, cleaning, laundry, use of different means of transport and self-managing medication, and handling money were evaluated. The maximum number of points was 8 . A smaller number of points scored in these tests reflects an inability to act independently in the basic activities (ADL) or more complex (IADL) ADL.

Using the "Timed Up \& Go" (TUG) test, ${ }^{25}$ three basic functions of everyday life were evaluated: recovering from a sitting position to a standing position, walking a short distance $(3 \mathrm{~m})$, and returning and moving to a sitting position. During the test, a patient performed the following operations as fast as they could: rise from a chair, walk a distance of $3 \mathrm{~m}$, turn back, walk to the chair, and sit back down on the chair. Time of operations was measured with the aid of a stopwatch. The patient performed the test twice. For the analysis, the best score was used. A short time to complete the test indicates good FA.

\section{Cognitive function and emotional status assessment}

Cognitive function were evaluated using the $\mathrm{MMSE},{ }^{26}$ which contains six groups of tasks to assess the level of functioning of the basic psychological processes such as orientation in time and place, memory, attention and counting, recall, language function, and constructional praxis.

The MMSE scores range from 0 to 30, higher scores indicating better cognitive functioning.

The participants' emotional status was evaluated using the 15 -item version of the GDS, ${ }^{27}$ characterizing the state of being of the subject in the previous 2 weeks. The GDS contains 15 "yes" or "no" questions characterizing the depressive status of the respondent. The raw scores range from 0 to 15 , where a higher score indicates deeper depression.

\section{Nutritional status assessment}

The nutritional status was assessed by the MNA. The MNA questionnaire contains 18 questions relating to the essential elements of nutritional status, such as food intake, loss of body weight, the ability to move around independently, the occurrence of acute disease or stress, neurological problems, body mass index, number of medications, and assessment of the arm and calf circumferences. The total number of points in the MNA questionnaire is 30 . A result $>23.5$ is treated as a satisfactory nutritional status, while a score $\leq 23.5$ suggests malnutrition. ${ }^{28}$

\section{PA measurements}

PA was evaluated using the Seven-Day Physical Activity Recall Questionnaire (SDPAR). ${ }^{29}$ The 7-day recall total score (daily energy expenditure over the past week) was calculated and used for further comparisons. 


\section{Statistical analysis}

A power calculation was performed to estimate the required sample size. The sample sizes required to detect differences of $10 \%$ in functional status and muscle function variables (with 0.80 power, 0.05 alpha type I error rate, and given baseline standard deviation [SD] values) were 10, 53, 36, 36, 34 , and 27 for ADL (1 point change), IADL ( 1 point change), TUG test, HGS, $P_{\max } / \mathrm{kg}$, and $v_{\text {opt }}$, respectively. Data were verified for normality of distribution (Shapiro-Wilk test) and equality of variances (Levene's test). A one-way analysis of variance and the Kruskal-Wallis test were used for comparison of sex groups. Pearson product moment or Spearman correlation coefficients were used to assess the relationship between two quantitative variables. A paired Student's $t$-test and sign test were used to determine the impact of the 1-year follow-up on dependent numeric variables. Multiple linear regression (with forward stepwise technique) including variables significant in bivariate analyses was used to identify independent variables that predict the changes of FAs during the 1-year follow-up. ADL, TUG, HGS, $\mathrm{P}_{\max } / \mathrm{kg}, v_{\text {opt }}$, and PA values were normalized using a log transformation for the purpose of statistical analyses. Effect sizes based on Cohen's $d$ were calculated. An effect size of 0.2 to $<0.5$ and $\geq 0.5$ to $<0.8$ has been suggested to represent a small and medium effect, respectively, while an effect size $\geq 0.8$ represents a large effect. For numeric variables, the results are presented as mean $\pm \mathrm{SD}$. The level of significance was set at $P \leq 0.05$ for all the analyses. The obtained data were statistically analyzed with the Statgraphics Plus 5 software package (Statpoint Technologies, Inc., Warrenton, VA, USA) and Statistica 12 software package (StatSoft, Cracow, Poland).

\section{Ethical considerations}

The proposal of this study was approved by the Bioethics Committee of the Medical University of Lodz, Poland (ref no $\mathrm{RNN} / 338 / 08 / \mathrm{KB}$ ). All the participants signed the informed consent form after hearing the explanation about the methods and aims of the study. All gathered data were confidential.

\section{Results}

\section{General characteristics of the study group}

The average age of the entire cohort was $69.8 \pm 9.0$ years. The mean number of years of education was $9.0 \pm 3.2$. The average number of regular medications taken was $6.46 \pm 2.95$ per day. Participants had been diagnosed with the following concomitant diseases: ischemic heart disease $(\mathrm{n}=25)$, arterial hypertension $(n=25)$, chronic heart failure $(n=24)$, history of stroke $(n=7)$, osteoarthritis $(n=16)$, eye diseases $(n=12)$, chronic obstructive pulmonary disease $(n=9)$, gastrointestinal diseases $(n=13)$, and depression $(n=12)$. Women were older than men and were characterized with significantly lower values of HGS, $\mathrm{P}_{\max } / \mathrm{kg}$, and $v_{\text {opt }}$ as compared with men, both at baseline and after the 1-year follow-up.

\section{Correlations between FA and independent variables at baseline and after the I-year follow-up}

The relationships of FA (ADL, IADL, and TUG test) to age, HGS, $\mathrm{P}_{\max } / \mathrm{kg}, v_{\text {opt }}$, GDS, MMSE, MNA, and PA in the study group at baseline and after the 1-year follow-up are presented by sex in Tables 1 and 2, respectively. At baseline, in women, FAs were related to almost all quantitative variables that are presented, excluding GDS and MMSE. In

Table I Correlations between FA and age, HGS, $P_{\max } / \mathrm{kg}, v_{\mathrm{opt}}$, GDS, MMSE, MNA, and PA in $4 \mathrm{I}$ older institutionalized adults at baseline

\begin{tabular}{|c|c|c|c|c|c|c|}
\hline \multirow[t]{2}{*}{ Quantitative variable } & \multicolumn{2}{|l|}{ ADL } & \multicolumn{2}{|l|}{ IADL } & \multicolumn{2}{|l|}{ TUG } \\
\hline & Women $(n=17)$ & Men $(n=24)$ & Women $(n=17)$ & Men $(n=24)$ & Women $(n=17)$ & Men $(n=24)$ \\
\hline Age (years) & $-0.50 *$ & -0.25 & $-0.59 *$ & -0.36 & $0.66 * *$ & 0.35 \\
\hline RHGS (kg) & 0.39 & 0.18 & 0.29 & 0.14 & $-0.48^{*}$ & -0.29 \\
\hline LHGS (kg) & 0.41 & 0.27 & $0.62 *$ & 0.25 & $-0.66 * *$ & -0.09 \\
\hline $\mathrm{P}_{\max } / \mathrm{kg}(\mathrm{W} / \mathrm{kg})$ & 0.36 & 0.04 & $0.57^{*}$ & 0.36 & $-0.64^{* *}$ & $-0.68 * *$ \\
\hline$v_{o p t}(r / m i n)$ & $0.50 *$ & -0.06 & $0.66^{*}$ & $0.48^{*}$ & $-0.75^{* *}$ & $-0.43^{*}$ \\
\hline GDS (points) & -0.23 & -0.04 & -0.31 & -0.24 & 0.36 & 0.32 \\
\hline MMSE (points) & 0.24 & -0.10 & 0.19 & 0.20 & -0.25 & -0.01 \\
\hline MNA (points) & $0.5 I^{*}$ & -0.06 & 0.32 & 0.01 & -0.22 & -0.02 \\
\hline PA (kcal/kg/day) & $0.4 I$ & 0.09 & $0.73 * *$ & 0.19 & $-0.50 *$ & -0.14 \\
\hline
\end{tabular}

Notes: $* P<0.05 . * * p<0.01$

Abbreviations: FA, functional ability; ADL, activities of daily living; IADL, instrumental activities of daily living; TUG, Timed UP \& Go; HGS, handgrip strength; RHGS, right handgrip strength; LHGS, left handgrip strength; $P_{\text {max }} / k g$, quadriceps muscle power; $v_{\text {opt }}$ optimal shortening velocity; GDS, Geriatric Depression Scale; MMSE, Mini-Mental Scale Examination; MNA, Mini Nutritional Assessment; PA, physical activity. 
Table 2 Correlations between FA and age, HGS, $P_{\max } / \mathrm{kg}, v_{\text {opt }}$, GDS, MMSE, MNA, and PA in 4 I older institutionalized adults at followup

\begin{tabular}{|c|c|c|c|c|c|c|}
\hline \multirow[t]{2}{*}{ Quantitative variable } & \multicolumn{2}{|l|}{ ADL } & \multicolumn{2}{|l|}{ IADL } & \multicolumn{2}{|l|}{ TUG } \\
\hline & Women $(n=17)$ & Men $(n=24)$ & Women $(n=17)$ & $\operatorname{Men}(n=24)$ & Women $(n=17)$ & Men $(n=24)$ \\
\hline Age (years) & $-0.49 *$ & -0.32 & -0.43 & -0.38 & $0.57^{*}$ & 0.24 \\
\hline RHGS (kg) & 0.39 & $0.42 *$ & 0.47 & 0.16 & -0.33 & -0.37 \\
\hline LHGS (kg) & 0.38 & 0.41 & $0.50 *$ & 0.34 & $-0.56 *$ & -0.31 \\
\hline$P_{\max } / \mathrm{kg}(\mathrm{W} / \mathrm{kg})$ & $0.5 I^{*}$ & 0.36 & $0.49 *$ & $0.48 *$ & $-0.53^{*}$ & $-0.60 * *$ \\
\hline$v_{o p t}(r / m i n)$ & $0.63 * *$ & $0.44^{*}$ & $0.53 *$ & $0.42 *$ & $-0.58^{*}$ & $-0.64 * *$ \\
\hline GDS (points) & -0.06 & -0.23 & -0.16 & -0.25 & 0.33 & 0.24 \\
\hline MMSE (points) & 0.37 & 0.19 & 0.34 & 0.15 & -0.07 & 0.11 \\
\hline MNA (points) & 0.20 & $0.57^{*}$ & $0.49 *$ & $0.56 *$ & -0.44 & -0.25 \\
\hline PA (kcal/kg/day) & $0.60 *$ & $0.66 * *$ & $0.62 * *$ & $0.47 *$ & $-0.72 * *$ & -0.38 \\
\hline
\end{tabular}

Notes: $* P<0.05$. $* * P<0.01$.

Abbreviations: FA, functional ability; ADL, activities of daily living; IADL, instrumental activities of daily living; TUG, Timed Up \& Go; HGS, handgrip strength; RHGS, right handgrip strength; LHGS, left handgrip strength; $P_{\max } / \mathrm{kg}$, quadriceps muscle power; $v_{o p t}$, optimal shortening velocity; GDS, Geriatric Depression Scale; MMSE, Mini-Mental Scale Examination; MNA, Mini Nutritional Assessment; PA, physical activity.

men, FAs were related only to $\mathrm{P}_{\max } / \mathrm{kg}$ and $v_{\text {opt }}$. At follow-up, both in women and in men, FAs were related to almost all quantitative variables that are presented, excluding GDS and MMSE. For all significant correlation coefficients presented in Tables 1 and 2, effect sizes were large (Cohen's $d$ varied from 0.7 to $>2$ ) with the exception of the association between IADL and PA in men at follow-up (Cohen's $d=0.26$ ).

Muscle strength and power measurements were generally inversely related to age (not shown in the table). In women, $\mathrm{P}_{\max } / \mathrm{kg}$ (Figure 1$)$ and $v_{\text {opt }}(\rho=-0.79 ; P<0.001$ and $\rho=-0.69$; $P<0.01$, respectively) were strongly adversely correlated with age, both at baseline and at follow-up. In men, only the association of $v_{\text {opt }}$ with age at baseline reached the statistical significance level $(\rho=-0.43 ; P<0.05)$. In women, HGS was

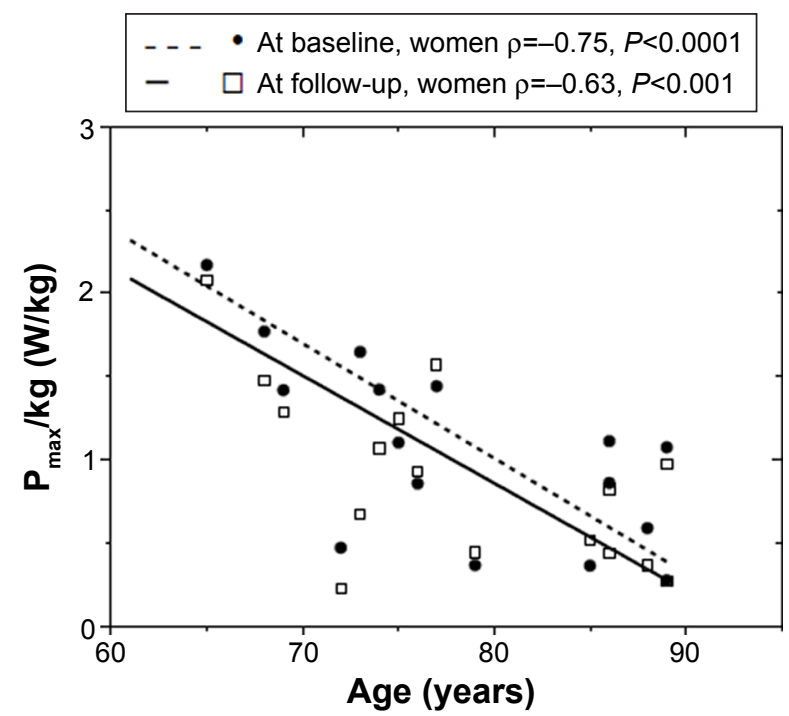

Figure I Correlation between the $\mathrm{P}_{\max } / \mathrm{kg}(\mathrm{W} / \mathrm{kg})$ and age in 17 older inactive women at baseline and at I-year follow-up.

Abbreviation: $\mathrm{P}_{\max } / \mathrm{kg}$, quadriceps muscle power. also inversely related to age ( $\rho$ ranged from -0.53 to -0.73 ) both at baseline and at follow-up. HGS, $\mathrm{P}_{\max } / \mathrm{kg}$, and $v_{\text {opt }}$ were generally not related to PA (but with positive trend), with only the LHGS-PA association $(\rho=0.54 ; P<0.05)$ in women reaching the statistical significance level at baseline (not shown in the table).

\section{Multiple regression analysis by sex at baseline and after the I-year follow-up}

All the statistically significant predictors (independent variables) of FA (dependent variables) in Tables 1 and 2 were subjected to multiple regression analysis.

At baseline, in the group of women, ADL was favorably predicted by $v_{\text {opt }}$ :

$$
\begin{aligned}
\log \mathrm{ADL}= & 1.449+0.0823 \\
& \times \log \mathrm{v}_{\text {opt }}\left(\text { adjusted } R^{2}=18.6 \%\right)
\end{aligned}
$$

IADL was favorably predicted by $v_{\text {opt }}$ and PA:

$$
\begin{aligned}
\mathrm{IADL}= & -39.91+1.85 \times \log v_{\text {opt }} \\
& \left.+10.67 \times \log \text { PA (adjusted } R^{2}=50.4 \%\right)
\end{aligned}
$$

TUG test was favorably (inversely) predicted only by $v_{\text {opt }}$ :

$$
\begin{aligned}
\log \text { TUG test }= & 4.69-0.692 \\
& \times \log v_{\mathrm{opt}}\left(\text { adjusted } R^{2}=51.1 \%\right)
\end{aligned}
$$

At baseline, in the group of men, IADL was favorably predicted by $v_{\text {opt }}$ :

$$
\begin{aligned}
\mathrm{IADL}= & -11.7+3.91 \\
& \times \log v_{\mathrm{opt}}\left(\text { adjusted } R^{2}=21.6 \%\right)
\end{aligned}
$$


TUG test was favorably (inversely) predicted by $\mathrm{P}_{\max } / \mathrm{kg}$ :

$\log$ TUG test $=3.25-0.856$

$$
\times \log \mathrm{P}_{\max } / \mathrm{kg} \text { (adjusted } R^{2}=48.7 \% \text { ) }
$$

At follow-up, in the group of women, ADL was favorably predicted only by $v_{\mathrm{opt}}$ :

$$
\begin{aligned}
\log \mathrm{ADL}= & 0.883+0.24 \\
& \times \log \mathrm{v}_{\mathrm{opt}}\left(\text { adjusted } R^{2}=41.0 \%\right)
\end{aligned}
$$

IADL was favorably predicted by PA:

$$
\begin{aligned}
\mathrm{IADL}= & -57.4+17.4 \\
& \times \log \mathrm{PA}\left(\text { adjusted } R^{2}=34.5 \%\right)
\end{aligned}
$$

TUG test was favorably (inversely) predicted by $v_{\text {opt }}$ and PA:

$$
\begin{aligned}
\log \text { TUG test }= & 14.1-0.294 \times \log \mathrm{v}_{\mathrm{opt}}-2.99 \\
& \times \log \mathrm{PA}\left(\text { adjusted } R^{2}=61.9 \%\right)
\end{aligned}
$$

At follow-up, in the group of men, ADL was favorably predicted by $v_{\text {opt }}$, MNA, and PA:

$$
\begin{aligned}
\log \mathrm{ADL}= & -2.54+0.153 \times \log \mathrm{v}_{\text {opt }}+0.73 \times \mathrm{MNA} \\
& +0.383 \times \log \mathrm{PA}\left(\text { adjusted } R^{2}=68.3 \%\right)
\end{aligned}
$$

IADL was favorably predicted by $\mathrm{P}_{\max } / \mathrm{kg}, \mathrm{MNA}$, and PA:

$$
\begin{aligned}
\mathrm{IADL}= & -35.9+1.68 \times \log \mathrm{P}_{\max } / \mathrm{kg}+0.718 \times \mathrm{MNA} \\
& +6.29 \times \log \mathrm{PA}\left(\text { adjusted } R^{2}=52.7 \%\right)
\end{aligned}
$$

TUG test was favorably (inversely) predicted by $v_{\text {opt }}$ :

$$
\begin{aligned}
\log \text { TUG test }= & 6.66-1.031 \\
& \times \log v_{\mathrm{opt}}\left(\text { adjusted } R^{2}=34.2 \%\right)
\end{aligned}
$$

\section{Comparison of the test results at follow-up}

Table 3 presents the impact of 1-year follow-up on FA, HGS, $P_{\max } / \mathrm{kg}, v_{\text {opt }}$, GDS, MMSE, MNA, and PA in 41 older people. At follow-up, the deterioration of ADL, TUG test, $\mathrm{P}_{\max } / \mathrm{kg}, v_{\mathrm{opt}}$, and PA reached the statistical significance level. Effect sizes for changes in IADL, HGS, GDS, and MMSE at the 1-year follow-up were small, but close to medium for ADL, TUG test, $\mathrm{P}_{\max } / \mathrm{kg}, \mathrm{v}_{\text {opt }}$, MNA, and PA according to standard criteria. ${ }^{30}$

Changes in FA during the 1-year follow-up were not related to changes in HGS, $\mathrm{P}_{\max } / \mathrm{kg}$, and $v_{\text {opt }}$, or fluctuations in PA level, assessed either jointly or separately in both sexes.

\section{Discussion}

\begin{tabular}{|c|c|c|c|c|}
\hline Variable & $\begin{array}{l}\text { At baseline } \\
(n=4 I)\end{array}$ & $\begin{array}{l}\text { At follow-up } \\
(n=4 I)\end{array}$ & $\begin{array}{l}\text { Statistical significance } \\
\text { (P-value) }\end{array}$ & $\begin{array}{l}\text { Effect size } \\
\text { (Cohen's d) }\end{array}$ \\
\hline ADL (points) & $5.76 \pm 0.36$ & $5.5 I \pm 0.67$ & $<0.01$ & 0.46 \\
\hline IADL (points) & $4.4 I \pm 2.14$ & $4.15 \pm 2.30$ & NS & 0.12 \\
\hline TUG test (s) & $12.10 \pm 5.86$ & $|3.6| \pm 7.93$ & $<0.05$ & 0.22 \\
\hline RHGS (kg) & $32.98 \pm|3.2|$ & $32.20 \pm 11.60$ & NS & 0.06 \\
\hline LHGS (kg) & $30.63 \pm 13.30$ & $30.29 \pm 11.63$ & NS & 0.03 \\
\hline $\mathrm{P}_{\max } / \mathrm{kg}(\mathrm{W} / \mathrm{kg})$ & $2.17 \pm 1.26$ & $1.86 \pm 1.20$ & $<0.001$ & 0.25 \\
\hline$v_{o p t}(r / m i n)$ & $49.94 \pm 21.18$ & $46.09 \pm 18.95$ & $<0.05$ & 0.19 \\
\hline GDS (points) & $6.37 \pm 3.11$ & $6.34 \pm 3.21$ & NS & 0.01 \\
\hline MMSE (points) & $24.07 \pm 4.55$ & $24.02 \pm 5.94$ & NS & 0.01 \\
\hline MNA (points) & $22.7 I \pm 3.17$ & $22.07 \pm 2.25$ & NS & 0.23 \\
\hline PA (kcal/kg/day) & $36.28 \pm 3.27$ & $35.74 \pm 3.79$ & $<0.05$ & 0.15 \\
\hline
\end{tabular}

According to our knowledge, no prospective studies evaluating the relationship between FA and HGS, $\mathrm{P}_{\text {max }}$, and $v_{\text {opt }}$ among older institutionalized adults have been carried out previously. This study is the first to show that the FAs of older institutionalized adults are largely related to $\mathrm{P}_{\max }$ and $v_{\text {opt }}$, while the other two physiological measures are clearly age-dependent. As compared to $\mathrm{P}_{\max }$ and $v_{\text {opt}}$, HGS has a much weaker association with the FA of older institutionalized adults.

In general, muscle strength reduction is particularly pronounced after the age of 50, and it is after the age of

Table 3 Impact of I-year follow-up on FA, HGS, $P_{\text {max }} / k g, v_{\text {opt }}$, GDS, MMSE, MNA, and PA in 4 I older institutionalized adults

Note: Data are represented as mean \pm standard deviation unless stated otherwise.

Abbreviations: FA, functional ability; ADL, activities of daily living; IADL, instrumental activities of daily living; TUG, Timed UP \& Go; HGS, handgrip strength; RHGS, right handgrip strength; LHGS, left handgrip strength; $P_{\max } / \mathrm{kg}$, quadriceps muscle power; $v_{\text {opt }}$ optimal shortening velocity; GDS, Geriatric Depression Scale; MMSE, Mini-Mental Scale Examination; MNA, Mini Nutritional Assessment; PA, physical activity; NS, statistically insignificant. 
70 that losses reach a critical point. ${ }^{31}$ Based on a 25 -year prospective study of the Honolulu Heart Program including over 6,000 healthy men aged 45-68 years, it was found that the level of HGS is an effective predictor of disability in initially healthy men. ${ }^{32}$ The risk of disability in old age ( 25 years after the first study) was twice as high in men, with low levels of strength identified in the first study compared with men presenting high output strength levels. Higher levels of muscle strength in the hands determine the possibility to perform more complex IADL tasks. Another study conducted by Aoyama et $a{ }^{33}$ showed a significant correlation between HGS and the TUG test. Our data show that HGS was moderately associated with the indices of FA, mainly in women. $P_{\max }$ and, especially, $v_{\text {opt }}$ were more important correlates of FA than HGS, both at baseline and at the 1-year follow-up in both sexes.

Our findings are consistent with other studies comparing the relationship between muscle strength, power, and $v_{\text {opt }}$ with FA. ${ }^{11}$ Some of those studies report that, although muscle strength and power are strongly related to each other, they can determine FA to a different degree. Many ADLs require the ability to perform short, intensive exercises, which demand the generation of appropriate muscle power. ${ }^{15,34,35}$ FA depends largely on how quickly the muscles can generate strength, not only on how strong they are. ${ }^{34}$ This may be due to the fact that ADLs require more complex muscle activity than just the slow development of strength. ${ }^{36}$ Optimal shortening velocity and the ability to develop power are firmly linked to the amount of fast-twitch muscle fibers (FT, Type II). ${ }^{37}$ Their number decreases with advancing age and is accompanied by a slowdown of muscle contraction, leading to a greater decline of maximum short-term power with age, and this decline is more heavily related to the loss of FA than the decrease of muscle strength. ${ }^{20,22,38}$ In studies comparing the relationships of strength and muscle power to FA, muscle power almost always appears to be a stronger determinant. ${ }^{10,38,39}$ In older adults, $\mathrm{P}_{\text {max }}$ is accountable to a greater extent for the volatility of the results in FA than muscle strength, in particular during low-intensity activities such as walking. ${ }^{40}$ Kostka et al ${ }^{4}$ studied the effect of muscle strength, power, and $v_{\text {opt }}$ on the FA of elderly women with chronic osteoarthritis. Muscle power and $v_{\text {opt }}$ correlated with functional tests such as ADL, TUG test, Tinetti test, and the 6-MWT (6-minute walking test); there was no correlation of muscle strength with FAs. Clémençon et $\mathrm{a}^{41}$ also assessed the impact of strength, power, and $v_{\text {opt }}$ of the knee extensor muscles on the FAs of older women. Similarly, only muscle power and $v_{\text {opt }}$ but not strength correlated with functional tests. Those authors suggest that the assessment of power and $v_{\text {opt }}$ is a better indicator of FA in older women than muscle strength.

In the present study, at the 1-year follow-up, deterioration of $\mathrm{P}_{\max }$ and $v_{\text {opt }}$ and a deterioration in the results of functional tests such as ADL and TUG were observed, with a concomitant decline of PA. When assessed cross-sectionally, a lower level of PA was related to lower FA. Such an importance of PA in preserving FAs of older subjects has been shown in numerous previous studies. ${ }^{42,43}$ On the other hand, PA was not associated to $\mathrm{P}_{\max }$ or $v_{\text {opt }}$ either at baseline or at follow-up, and 1-year changes in FA, $\mathrm{P}_{\max }$, and $v_{\text {opt }}$ were not related to fluctuations of PA. These negative results may be, at least partially, explained by the inactivity and homogeneity of our studied groups. Several studies found positive impact of PA on muscle power, with study protocols lasting from 3 weeks to 12 weeks. ${ }^{4,44} 47$ Interesting findings were presented by Fatourus et al. ${ }^{48}$ They found that the higher the intensity of the training, the higher the increase in anaerobic power of older men. Such an intensive training, by stressing the muscle with rapid movements, would probably be beneficial for $\mathrm{P}_{\max }$. Furthermore, such a training regimen may lead to general health benefits for a prolonged period after the training ceases. Our prospective data seem to confirm this information and further indicates that in inactive elders, cross-sectional associations between $\mathrm{P}_{\text {max }}, v_{\text {opt }}$ and FA persist but no apparent relationships exist concerning time-related changes. Therefore, formalized exercise training should be probably applied in this population to achieve muscle $\mathrm{P}_{\text {max }}$ and $v_{\text {opt }}$ improvements related to functional gains.

Together with associations between muscle physiological properties and FA, our results show a moderate relationship between FA and nutritional status. Proper nutrition, by ensuring an adequate level of nutrients and preventing malnutrition, is conducive to maintaining a satisfactory level of FA. ${ }^{49-51}$ Worldwide, malnutrition has become a common problem among the elderly. Older people living in institutions are most vulnerable to malnutrition. ${ }^{52}$ For instance, one study showed that $\sim 67 \%$ of older adults in nursing homes were malnourished. ${ }^{53}$ Malnutrition is associated with the progressive deterioration of the FAs of older adults, ${ }^{49}$ and a factor leading to disability. ${ }^{50,51}$

\section{Conclusion}

The present study has demonstrated that $\mathrm{P}_{\max }$ and $v_{\text {opt }}$ are important correlates of FAs of older, inactive adults in a long-term care home. When assessed cross-sectionally, 
$\mathrm{P}_{\max }$ and $v_{\text {opt }}$ are adversely related to age and positively associated with FA. Furthermore, the relationship of $\mathrm{P}_{\max }$ and $v_{\text {opt }}$ to functional status is stronger than that of HGS, both at baseline and after the 1-year follow-up. Declining PA levels of older adults are accompanied by decreasing FA, $P_{\max }$, and $v_{\text {opt }}$. Nevertheless, 1-year changes in FA were not related to changes in muscle strength, power, and $v_{\text {opt }}$ or fluctuations in PA level. Further studies are needed to explore the potential possibilities of alleviating functional decline by protecting muscle function in long-term care residents.

\section{Study limitations}

This study has several limitations, including 1) the relatively small sample of participants, 2) the lack of an intervention group, 3) some moderate effect sizes, 4) relatively low average age of participants, and 5) the homogeneity of studied group and their reluctance to perform any PA (especially in women). On the other hand, the final point may be also considered as a strength of the present study, as it demonstrates the lack of benefits from habitual variations of PA and indicates the need for structured exercise programs. Bearing in mind these limitations, the present study requires caution in data interpretation and should be confirmed in future studies.

\section{Acknowledgments}

We thank Dr Krystyna Matysek, Director of the Rehabilitation and Care Centre (CRO), Lodz, Poland, for providing us the opportunity to perform this work. We are also grateful to Danuta Zając and the entire medical staff of CRO for their help in this study. We acknowledge the support of Dr Joanna Kostka during the analysis of power testing and thank all the subjects for their participation and commitment to the study. This work was supported by the Healthy Ageing Research Centre project (REGPOT-2012-2013-1, 7FP) and Integrated Program of Operational Regional Development (2.6) within the project entitled "Grants to support the innovative research of doctoral students".

\section{Disclosure}

The authors declare no conflicts of interest in this work.

\section{References}

1. Muhlberg W, Sieber C. Sarcopenia and frailty in geriatric patients: implications for training and prevention. Z Gerontol Geriatr. 2004; 37(1):2-8.

2. Conradsson M, Littbrand H, Boström G, Lindelöf N, Gustafson Y, Rosendahl E. Is a change in functional capacity or dependency in activities of daily living associated with a change in mental health among older people living in residential care facilities? Clin Interv Aging. 2013;8: $1561-1568$
3. Dias FM, Costa SO, Pereira de Freitas J, Pinto Ada C, Vigário Pdos S, Mainenti MR. Functional capacity of oldest old living in a long-stay institution in Rio De Janeiro, Brazil. J Phys Ther Sci. 2014;26(7): 1097-1105.

4. Kostka JS, Czernicki JW, Kostka TJ. Association of muscle strength, power, and optimal shortening velocity with functional abilities of women with chronic osteoarthritis participating in a multi-modal exercise program. J Aging Phys Act. 2014;22(4):564-570.

5. Blain H, Carriere I, Sourial N, et al. Balance and walking speed predict subsequent 8-year mortality independently of current and intermediate events in well-functioning women aged 75 years and older. $J$ Nutr Health Aging. 2010;14(7):595-600.

6. Hermsen LA, Leone SS, Smalbrugge M, Dekker J, van der Horst HE. Frequency, severity and determinants of functional limitations in older adults with joint pain and comorbidity: results of a cross-sectional study. Arch Gerontol Geriatr. 2014;59(1):98-106.

7. Abellan van Kan G, Rolland Y, Andrieu S, et al. Gait speed at usual pace as a predictor of adverse outcomes in community dwelling older people an International Academy on Nutrition and Aging (IANA) Task Force. J Nutr Health Aging. 2009;13(10):881-889.

8. Del Duca GF, Silva SG, Thumé E, Santos IS, Hallal PC. Predictive factors for institutionalization of the elderly: a case-control study. Rev Saude Publica. 2012;46(1):147-153.

9. Avelino-Silva TJ, Farfel JM, Curiati JA, Amaral JR, Campora F, Jacob-Filho W. Comprehensive geriatric assessment predicts mortality and adverse outcomes in hospitalized older adults. BMC Geriatr. 2014; 3(14):129.

10. Puthoff ML, Janz KF, Nielson D. The relationship between lower extremity strength and power to everyday walking behaviors in older adults with functional limitations. J Geriatr Phys Ther. 2008;31:24-31.

11. Reid KF, Naumova EN, Carabello RJ, Phillips EM, Fielding RA. Lower extremity muscle mass predicts functional performance in mobilitylimited elders. J Nutr Health Aging. 2008;12(7):493-498.

12. Rantanen T. Muscle strength, disability and mortality. Scand J Med Sci Sports. 2003;13(1):3-8.

13. Innes E. Handgrip strength testing: review of the literature. Aust Occup Ther J. 1999;46:120-140.

14. Marsh AP, Miller ME, Rejeski WJ, Hutton SL, Kritchevsky SB. Lower extremity muscle function after strength or power training in older adults. J Aging Phys Act. 2009;17(4):416-443.

15. Kostka T, Rahmani A, Berthouze SE, et al. Quadriceps muscle function in relation to habitual physical activity and V02max in men and women aged more than 65 years. J Gerontol A Biol Sci Med Sci. 2000; 55:B481-B488.

16. Sayers SP, Guralnik JM, Thombs LA, Fielding RA. Effect of leg muscle contraction velocity on functional performance in older men and women. J Am Geriatr Soc. 2005;53(3):467-471.

17. Brunner F, Schmid A, Sheikhzadeh A, Nordin M, Yoon J, Frankel V. Effects of aging on Type II muscle fibers: a systematic review of the literature. J Aging Phys Act. 2007;15(3):336-348.

18. Kostka T. Quadriceps maximal power and optimal shortening velocity in 335 men aged 23-88 years. Eur J Appl Physiol. 2005;95(2-3):140-145.

19. Teraoka T. Studies on the peculiarity of grip strength in relation to body positions and aging. Kobe J Med Sci. 1979;25(1):1-17.

20. Bonnefoy M, Kostka T, Arsac LM, Berthouze SE, Lacour JR. Peak anaerobic power in elderly men. Eur J Appl Physiol Occup Physiol. 1998; 77(1-2):182-188.

21. Lakomy HK. Measurements of work and power output using frictionloaded cycle ergometers. Ergonomics. 1986;29(4):509-517.

22. Kostka T, Bonnefoy M, Arsac LM, Berthouze SE, Belli A, Lacour JR. Habitual physical activity and peak anaerobic power in elderly women. Eur J Appl Physiol Occup Physiol. 1997;76(1):81-87.

23. Katz S, Ford AB, Moskowitz RW, et al. Studies of illness in the aged: the index of ADL, a standardized measure of biological and psychosocial function. JAMA. 1963;185:914-919.

24. Lawton MP, Brody EM. Assessment of older people: self-maintaining and instrumental activities of daily living. Gerontologist. 1969;9: 179-186. 
25. Podsiadło D, Richardson S. The timed "up \& go": a test of basic functional mobility for frail elderly persons. J Am Geriatr Soc. 1991;39(2): 142-148.

26. Folstein MF, Folstein SE, McHugh PR. "Mini-Mental State": a practical method for grading the cognitive state of patients for the clinician. J Psychiatr Res. 1975;12(3):189-198.

27. Yesavage JA, Brink TL, Rose TL. Development and validation of a geriatric depression screening scale: a preliminary report. J Psychiatr Res. 1983;17(1):37-49.

28. Rubenstein LZ, Harker JO, Salvà A, Guigoz Y, Vellas B. Screening for undernutrition in geriatric practice: developing the short-form mini-nutritional assessment (MNA-SF). J Gerontol A Biol Sci Med Sci. 2001;56(6):M366-M372.

29. Blair SN, Haskell WL, Ho P, et al. Assessment of habitual physical activity by a seven-day recall in a community survey and controlled experiments. Am J Epidemiol. 1985;122:794-804.

30. Cohen J. Statistical Power Analysis for the Behavioral Sciences. 2nd ed. Hillsdale NJ: Lawrence Erlbaum; 1988.

31. Mazzeo R, Cavanagh P, Evans W, et al. American College of Sports Medicine Position Stand. Exercise and physical activity for older adults. Med Sci Sports Exerc. 1998;30(6):992-1008.

32. Rantanen T, Guralnik JM, Foley D, et al. Midlife hand grip strength as a predictor of old age disability. JAMA. 1999;281(6):558-560.

33. Aoyama M, Suzuki Y, Onishi J, Kuzuya M. Physical and functional factors in activities of daily living that predict falls in communitydwelling older women. Geriatr Gerontol Int. 2011;11(3):348-357.

34. Bottaro M, Machado SN, Nogueira W, Scales R, Veloso J. Effect of high versus low-velocity resistance training on muscular fitness and functional performance in older men. Eur J Appl Physiol. 2007;99(3): 257-264.

35. Hazell T, Kenno K, Jakobi J. Functional benefit of power training for older adults. J Aging Phys Act. 2007;15(3):349-359.

36. Barry BK, Carson RG. The consequences of resistance training for movement control in older adults. J Gerontol A Biol Sci Med Sci. 2004; 59(7):730-754.

37. Hautier CA, Linossier MT, Belli A, Lacour JR, Arsac LM. Optimal velocity for maximal power production in non-isokinetic cycling is related to muscle fibre type composition. Eur J Appl Physiol Occup Physiol. 1996;74(1-2):114-118.

38. Bean JF, Leveille SG, Kiely DK, Bandinelli S, Guralnik JM, Ferrucci L. A comparison of leg power and leg strength within the InCHIANTI study: which influences mobility more? J Gerontol A Biol Sci Med Sci. 2003;58(8):728-733.

39. Cuoco A, Callahan DM, Sayers S, Frontera WR, Bean J, Fielding RA. Impact of muscle power and force on gait speed in disabled older men and women. J Gerontol A Biol Sci Med Sci. 2004;59(11):1200-1206.

40. Foldvari M, Clark M, Laviolette LC, et al. Association of muscle power with functional status in community-dwelling elderly women. J Gerontol A Biol Sci Med Sci. 2000;55(4):M192-M199.
41. Clémençon M, Hautier CA, Rahmani A, Cornu C, Bonnefoy M. Potential role of optimal velocity as a qualitative factor of physical functional performance in women aged 72 to 96 years. Arch Phys Med Rehabil. 2008;89(8):1594-1599.

42. de Souza Santos CA, Dantas EE, Moreira MH. Correlation of physical aptitude; functional capacity, corporal balance and quality of life (QoL) among elderly women submitted to a post-menopausal physical activities program. Arch Gerontol Geriatr. 2011;53(3):344-349.

43. Gianoudis J, Bailey CA, Daly RM. Associations between sedentary behavior and body composition, muscle function and sarcopenia in community-dwelling older adults. Osteoporos Int. 2015;26(2):571-579.

44. Yu CH, Kim UR, Kwon TK. Fundamental study of basal physical fitness and activities of daily living for the aged in relation to indoor horse riding exercise. Biomed Mater Eng. 2014;24(6):2407-2415.

45. Regterschot GR, Folkersma M, Zhang W, Baldus H, Stevens M, Zijlstra W. Sensitivity of sensor-based sit-to-stand peak power to the effects of training leg strength, leg power and balance in older adults. Gait Posture. 2014;39(1):303-307.

46. Gschwind YJ, Kressig RW, Lacroix A, Muehlbauer T, Pfenninger B, Granacher U. A best practice fall prevention exercise program to improve balance, strength/power, and psychosocial health in older adults: study protocol for a randomized controlled trial. BMC Geriatr. 2013;13:105.

47. Cadore EL, Casas-Herrero A, Zambom-Ferraresi F, et al. Multicomponent exercises including muscle power training enhance muscle mass, power output, and functional outcomes in institutionalized frail nonagenarians. Age (Dordr). 2014;36(2):773-785.

48. Fatourus IG, Kambas A, Katrabasas I, et al. Strength training and detraining effects on muscular strength, anaerobic power, and mobility of inactive older men are intensity dependent. Br J Sports Med. 2005;39(10):776-780.

49. Vivanti A, Ward N, Haines T. Nutritional status and associations with falls, balance, mobility, and functionality during hospital admission. J Nutr Health Aging. 2011;15(5):388-391.

50. Martínez-Reig M, Gómez-Arnedo L, Alfonso-Silguero SA, JuncosMartínez G, Romero L, Abizanda P. Nutritional risk, nutritional status and incident disability in older adults. The FRADEA study. $J$ Nutr Health Aging. 2014;18(3):270-276.

51. Singh DK, ManafZA, Yusoff NA, Muhammad NA, Phan MF, Shahar S. Correlation between nutritional status and comprehensive physical performance measures among older adults with undernourishment in residential institutions. Clin Interv Aging. 2014;25(9):1415-1423.

52. Patel MD, Martin FC. Why don't elderly hospital inpatients eat adequately? J Nutr Health Aging. 2008;12(4):227-231.

53. Kaiser MJ, Bauer JM, Rämsch C, et al. Frequency of malnutrition in older adults: a multinational perspective using the mini nutritional assessment. J Am Geriatr Soc. 2010;58(9):1734-1738.
Clinical Interventions in Aging

\section{Publish your work in this journal}

Clinical Interventions in Aging is an international, peer-reviewed journal focusing on evidence-based reports on the value or lack thereof of treatments intended to prevent or delay the onset of maladaptive correlates of aging in human beings. This journal is indexed on PubMed Central, MedLine,

\section{Dovepress}

CAS, Scopus and the Elsevier Bibliographic databases. The manuscript management system is completely online and includes a very quick and fair peer-review system, which is all easy to use. Visit http://www.dovepress. com/testimonials.php to read real quotes from published authors. 